\title{
Anti-obesity activity, acute toxicity, and chemical constituents of aqueous and ethanol Viola mandshurica extracts
}

\author{
Yoon-Young Sung ${ }^{1}$, Dong-Seon $\mathrm{Kim}^{2}$, Seung-Hyung Kim³ and Ho Kyoung Kim*
}

\begin{abstract}
Background: Viola mandshurica has traditionally been used as an expectorant, diuretic, and anti-inflammatory drug. The present study was designed to test the hypothesis that low doses of two different $V$. mandshurica extracts have anti-obesity effects.

Methods: We evaluated the effects of ethanol extract (VME) and aqueous extract (VMA) from V. mandshurica on high-fat diet (HFD)-induced obese mice as well as the acute oral toxicities and chemical compositions of both extracts.

Results: Oral administration of VME or VMA (50, 100, or $200 \mathrm{mg} / \mathrm{kg}$ ) decreased body weight gain, liver and adipose tissue mass, adipocyte size, and serum lipid levels. Both extracts increased adiponectin serum concentrations and mRNA expression in epididymal adipose tissue. VME and VMA also reversed the HFD-induced mRNA expression of lipogenic genes such as CCAAT/enhancer binding protein (C/EBP)a, C/EBP $\beta$, sterol regulatory element-binding protein $1 \mathrm{C}$, and leptin in adipose tissue, whereas they increased mRNA expression of uncoupling protein 2 and adenosine monophosphate-activated protein kinase (AMPK). VME and VMA increased the phosphorylation of AMPK and acetyl-coA carboxylase with a concomitant decrease in fat accumulation in the liver. High performance liquid chromatography analysis revealed that both VME and VMA contained esculetin ( $0.566 \%$ for VME, $0.231 \%$ for VMA) and schaftoside $(0.147 \%$ for VME, $0.126 \%$ for VMA). In a 2-week acute toxicity study, administration of a single oral dose of VME or VMA (5000 mg/kg) caused no signs of toxicity or mortality.
\end{abstract}

Conclusions: These results suggest that both VM extracts exert anti-obesity effects in HFD-induced obese mice by suppressing lipogenesis and activating AMPK in the liver and adipose tissue. Our findings suggest that VM extracts could be a safe and effective treatment for obesity.

Keywords: Adiponectin, Adipose tissue, AMP-activated protein kinase, Liver, Toxicity

\section{Background}

Obesity is a major public health problem in developed countries because it conveys an increased risk of chronic metabolic diseases such as type 2 diabetes and coronary heart disease [1]. Various approaches to regulating obesity and weight have been suggested, including agents that inhibit nutrient absorption or appetite and induce weight loss [2]. Anti-obesity agents including orlistat, lorcaserin, phentermine/topiramate, and naltrexone/bupropion are currently approved for chronic weight management in

\footnotetext{
* Correspondence: hkkim@kiom.re.kr

${ }^{1}$ Mibyeong Research Center, Korea Institute of Oriental Medicine, 1672

Yuseong-daero, Yuseong-gu, Daejeon 305-811, Republic of Korea

Full list of author information is available at the end of the article
}

obese adults [3], but they have considerable side effects such as nausea, vomiting, insomnia, constipation, headache, stomachache, and gastrointestinal disturbance $[4,5]$. For these reasons, herbal medicines for weight control and obesity treatment have been used in many countries. Among them, extract obtained from Garcinia cambogia fruits containing hydroxycitric acid (HCA) has been routinely used for many centuries. Unlike chemical stimulants, it does not have toxic effects and is becoming a popular weight loss supplement $[6,7]$.

Viola mandshurica W. Becker is a perennial herb in the family Violaceae that is widely distributed in China, Korea, and Japan. It has traditionally been used because of its various pharmacological activities including diuretic, 
expectorant, and anti-inflammatory effects in conditions such as bronchitis, eczema, and skin eruptions [8]. Viola herbal extract is regarded to effectively clean blood components [9], and various studies show that $V$. mandshurica extract has potential anti-diabetic, anti-asthmatic, antioxidant, and neuroprotective activities $[8,10]$. We previously showed that oral administration of $V$. mandshurica ethanolic extract (VME, $400 \mathrm{mg} / \mathrm{kg} /$ day) suppresses body weight and lipid accumulation in adipose tissue in mice [11]. These results were the first evidence that VME can ameliorate obesity in vivo. Here, we performed further studies on the dose-dependency, toxicity, and chemical characterization of VME and $V$. mandshurica aqueous extract (VMA). We also tested the effects of lower doses $(50,100$, or $200 \mathrm{mg} / \mathrm{kg})$ of VME and VMA on fat accumulation in the liver and adipose tissue of high-fat diet (HFD)induced obese mice.

\section{Methods}

\section{Plant material extraction}

V. mandshurica was obtained as a dried whole plant from Omniherb Co. (Yeoungcheon, Korea) and authenticated using macroscopic and microscopic methods by the Classification and Identification Committee of the Korea Institute of Oriental Medicine. Voucher specimens (no. PH-88E, PH-88 W) were deposited at the herbarium of the Mibyeong research center at the Korea Institute of Oriental Medicine. V. mandshurica (100 g) was extracted twice with $70 \%$ ethanol or water using a 2 -h reflux extraction, and the extract was concentrated under reduced pressure. The concentrate was filtered, lyophilized, and subsequently stored at $4{ }^{\circ} \mathrm{C}$. The yields of the dried extract from starting crude materials were $11 \%$ and $19 \%(w / w)$ in $70 \%$ ethanol and water, respectively.

\section{High performance liquid chromatography (HPLC) analysis of VME and VMA}

The standard compounds esculetin (6,7-dihydroxycoumarin, purity 98\%) and schaftoside (6-C-beta-D-Glucosyl8-C-alpha-L-arabinosylapigenin, purity 98\%) were obtained from Sigma-Aldrich (St. Louis, MO, USA). HPLC-grade reagents, acetonitrile, and water were obtained from J. T. Baker (Phillipsburg, NJ, USA). All other chemicals used in this study were of reagent grade.

The chemical compositions of VME and VMA samples were analyzed by reverse phase-HPLC using a Waters Alliance 2695 system (Waters Co., Milford, MA, USA) coupled with a 2996 photodiode array detector. INNO C18 column (250 mm $\times 4.6 \mathrm{~mm}$; particle size $5 \mu \mathrm{m}$, Phenomenex (Young JIN Biochrom Co., Ltd., CA, Korea)) was used as stationary phase, and the mobile phase was composed of $0.1 \%(\mathrm{v} / \mathrm{v})$ trifluoroacetic acid/water (A) and acetonitrile (B). The gradient elution was optimized as shown in Table 1.
Table 1 Composition of mobile phase with gradient elution

\begin{tabular}{lll}
\hline Time (Min) & $\begin{array}{l}\text { A\% (0.1\% Trifluoroacetic } \\
\text { Acid in Water) }\end{array}$ & B\% (Actonitrile) \\
\hline $0-10$ & 90 & 10 \\
10 & 90 & 10 \\
50 & 50 & 50 \\
52 & 0 & 100 \\
58 & 0 & 100 \\
70 & 90 & 10 \\
70 & 90 & 10 \\
\hline
\end{tabular}

The flow rate was $1.0 \mathrm{~mL} / \mathrm{min}$, and the column temperature was $40{ }^{\circ} \mathrm{C}$. The injection volume was $20 \mu \mathrm{L}$.

Identification was based on retention time and UV spectra by comparison with commercial standards. Components were quantified based on peak areas at maximum wavelengths for each compound. Quantification was performed using a mixture of external standards of known concentration that were analyzed in duplicate before and after the batch of samples, and peak areas were used to calculate the sample contents of the compounds. A calibration curve of the standards ranging from 0.5 to $4.0 \mathrm{mg} / \mathrm{mL}$ (four levels) revealed good linearity, with $\mathrm{R}^{2}$ values exceeding 0.99 (peak areas vs. concentration).

\section{Animals and diets}

Seven-week-old male C57BL/6 J mice were purchased from Central Lab Animal Inc. (Seoul, Korea). Mice were housed in ventilated cages in an air-conditioned room at a temperature of $21 \pm 2{ }^{\circ} \mathrm{C}$ and humidity of $50 \pm 5 \%$ under a 12:12-h light/dark cycle. Mice were provided a commercial diet and water ad libitum for 1 week. All animal experiments were conducted in accordance with National Institutes of Health guidelines and approved by the Committee on Animal Care of the Daejeon University (Permit No. DJUARB2014-042). HFD mice were fed a diet (Rodent diet D12492, Research Diets, Inc., New Brunswick, NJ, USA) consisting of $60 \%$ fat, $20 \%$ protein, and $20 \%$ carbohydrate [12]. Normal control mice were fed a commercial standard diet (AIN-76A, Research Diets, Inc.) consisting of 11.5\% fat, $20.8 \%$ protein, and $67.7 \%$ carbohydrate.

Garcinia cambogia extract and orlistat (Orlistat, Roche, Mannheim, Germany) were used as positive controls. Mice were randomly divided into ten groups ( $n=12$ per group): (1) normal diet with vehicle (ND-normal), (2) HFD with vehicle (HFD-control), (3) HFD with VME $200 \mathrm{mg} / \mathrm{kg}$ (HFD-VME), (4) HFD with VME $100 \mathrm{mg} / \mathrm{kg}$, (5) HFD with VME $50 \mathrm{mg} / \mathrm{kg}$, (6) HFD with VMA $200 \mathrm{mg} / \mathrm{kg}$ (HFDVMA), (7) HFD with VMA $100 \mathrm{mg} / \mathrm{kg}$, (8) HFD with VMA $50 \mathrm{mg} / \mathrm{kg}$, (9) HFD with Orlistat (HFD-OR), and (10) HFD with Garcinia cambogia extract containing HCA (HFDHCA). VME, VMA, OR, and HCA were dissolved in normal saline and administered orally every day for 7 weeks. 
$\mathrm{OR}$ and $\mathrm{HCA}$ were given at 50 and $100 \mathrm{mg} / \mathrm{kg} /$ day, respectively. The OR dose for mice was calculated based on the human dose. Body weight and food intake were measured once per week. Food efficiency ratio (FER, \%) was calculated by the following formula: (body weight gain [g/day]/ food intake $[\mathrm{g} /$ day $]) \times 100$.

\section{Tissues weight and histological analysis}

At the end of the experimental period, mice were fasted for $15 \mathrm{~h}$ and then sacrificed. After blood collection, subcutaneous, epididymal, and kidney white adipose tissue and the liver, kidney, and spleen were removed and immediately weighed. For adipocyte staining, epididymal adipose tissue and the liver were fixed in $10 \%$ neutral formalin solution for $24 \mathrm{~h}$ and then embedded in paraffin. All tissue was cut to a thickness of $6 \mu \mathrm{m}$ and stained with hematoxylin and eosin (H\&E) or Oil Red O. Adipocyte size was determined from stained tissue sections under light microscopy (Olympus BX51, Olympus Optical Co., Tokyo, Japan). Immunohistochemistry was performed to evaluate AMPK and acetyl-coA carboxylase (ACC) activation in the liver. Phosphorylation of both proteins was detected in immersion-fixed paraffin-embedded sections of the liver using a 1:100 dilution of p-AMPK $\alpha$ rabbit antibody (Cell Signaling, Danvers, MA, USA) or pACC rabbit antibody (Cell Signaling) at $4{ }^{\circ} \mathrm{C}$ overnight.

\section{Serum biochemical parameter analysis}

Blood samples were centrifuged at $2000 \mathrm{~g}$ for $20 \mathrm{~min}$ at $4^{\circ}$

$\mathrm{C}$, and the serum was stored at $-70{ }^{\circ} \mathrm{C}$ until analysis.
Serum levels of triglyceride, free fatty acid, glucose, total cholesterol, high-density lipoprotein (HDL)-cholesterol, low-density lipoprotein (LDL)- cholesterol, alanine aminotransferase (ALT), aspartate aminotransferase (AST), and creatinine were analyzed with an automatic analyzer (Hitachi-720, Hitachi Medical, Japan). Serum leptin and adiponectin concentrations were measured with immunoassays using commercially available kits (Linco Research, St. Charles, MO, USA).

\section{Real-time reverse-transcriptase polymerase chain reaction (PCR)}

Total RNA from epididymal adipose tissue was isolated using a homogenizer and TRI reagent (Sigma-Aldrich). Total RNA $(5 \mu \mathrm{g})$ was used to synthesize cDNA with the First Strand cDNA Synthesis kit (Amersham Pharmacia, Little Chalfont, UK). Real-time quantitative PCR was performed using the Applied Biosystems 7500 Real-Time PCR system (Applied Biosystems, Foster City, CA, USA). The probes were labeled with the fluorescence reporter dye 6-carboxy-fluorescein (FAM, Applied Biosystems). The endogenous control was the mouse glyceraldehyde-3phosphate dehydrogenase (GAPDH) probe (VIC/MGB probe, primer limited, 4352339E, Applied Biosystems). PCR conditions were $2 \mathrm{~min}$ at $50{ }^{\circ} \mathrm{C}, 10 \mathrm{~min}$ at $94{ }^{\circ} \mathrm{C}, 15 \mathrm{~s}$ at $95{ }^{\circ} \mathrm{C}$, and $1 \mathrm{~min}$ at $45^{\circ} \mathrm{C}$ for 40 cycles. The expression levels of mRNA were normalized to those of GAPDH and calculated using the $2^{-\Delta \mathrm{Ct}}$ method according to the manufacturer's instructions. Specific primer sequences for target genes are shown in Table 2.

Table 2 Primer sequences

\begin{tabular}{|c|c|c|c|}
\hline Genes & Probe and Primer & Sequence & GenBank Accession Number \\
\hline \multirow[t]{2}{*}{ Leptin } & Forward & 5'-CCAAAACCCTCATCAAGACC-3' & \multirow[t]{2}{*}{ NM_008493 } \\
\hline & Reverse & 5'-GTCCAACTGTTGAAGAATGTCCC-3' & \\
\hline \multirow[t]{2}{*}{ UCP2 } & Forward & 5'-CCGCATTGGCCTCTACGACTCT-3' & \multirow[t]{2}{*}{ NM_011671 } \\
\hline & Reverse & 5'-CCCCGAAGGCAGAAGTGAAGTG-3' & \\
\hline \multirow[t]{2}{*}{ Adiponectin } & Forward & 5'-CCCAAGGGAACTTGTGCAGGTTGGATG-3' & \multirow[t]{2}{*}{ NM_009605.4 } \\
\hline & Reverse & 5'-GTTGGTATCATGGTAGAGAAGAAAGCC -3' & \\
\hline \multirow[t]{2}{*}{ C/EBPa } & Forward & 5'-TGGACAAGAACAGCAACGAGTAC-3' & \multirow[t]{2}{*}{ NM_001287523.1 } \\
\hline & Reverse & 5'-CGGTCATTGTCACTGGTCAACT-3' & \\
\hline \multirow[t]{2}{*}{$C / E B P \beta$} & Forward & 5'-AAGCTGAGCGACGAGTACAAGA-3' & \multirow[t]{2}{*}{ NM_001287739.1 } \\
\hline & Reverse & 5'-GTCAGCTCCAGCACCTTGTG-3' & \\
\hline \multirow[t]{2}{*}{ SREBP1C } & Forward & 5'-AGCCTGGCCATCTGTGAGAA-3' & \multirow[t]{2}{*}{ XM_006532714.2 } \\
\hline & Reverse & 5'-CAGACTGGTACGGGCCACAA-3' & \\
\hline \multirow[t]{2}{*}{ AMPK a1 } & Forward & 5'-AAGCCGACCCAATGACATCA-3' & \multirow[t]{2}{*}{ XM_011245321.1 } \\
\hline & Reverse & 5'-CTTCCTTCGTACACGCAAAT-3' & \\
\hline \multirow[t]{2}{*}{ AMPK a2 } & Forward & 5'-GATGATGAGGTGGTGGA-3' & \multirow[t]{2}{*}{ NM_178143.2 } \\
\hline & Reverse & 5'-GCCGAGGACAAAGTGC-3' & \\
\hline GAPDH & $\mathrm{VIC}$ & 5'-TGCATCCTGCACCACCAACTGCTTAG-3' & \\
\hline
\end{tabular}




\section{Acute toxicity test}

To meet guidelines for toxicity testing (2014-136) from Korea's Ministry of Food and Drug Safety (MFDS) at BIOTOXTECH, a Good Laboratory Practice institute, a single $5000 \mathrm{mg} / \mathrm{kg}$ dose was given to ten Sprague Dawley rats (five males and females, obtained from Orient Bio Inc., Seoul, Korea). Control rats were treated with vehicle. Animals were individually observed for clinical signs of toxicity, body weight change, and mortality at 30, 60, 120, 240 , and $360 \mathrm{~min}$ after dosing; periodically during the first $24 \mathrm{~h}$; and daily thereafter for a total of 14 days.

\section{Statistical analysis}

All data are presented as mean \pm standard error of the mean (SEM), and differences were considered statistically significant at $p<0.05$. Differences between groups were examined using unpaired Student's $t$-tests and analyses of variance (ANOVA) followed by Duncan's multiple range tests.

\section{Results}

Effects of VME and VMA on body weight, FER, and organ weights

Figure 1 shows body weight (g), FER (\%), and final organ weight (g) during the 7-week experimental period. After 7 weeks, the HFD group had a higher mean body weight than the ND group, but oral administration of VME or VMA reduced body weight in HFD mice (Fig. 1a-b) without changing food intake (data not shown). The mean FER was significantly higher in the HFD group than in the ND group, but oral administration of VME or VMA at doses of 100 and $200 \mathrm{mg} / \mathrm{kg}$ reduced FER (Fig. 1c). The weights of abdominal subcutaneous, epididymal, and kidney adipose tissue were significantly increased in the HFD group, but VME or VMA at $200 \mathrm{mg} / \mathrm{kg}$ decreased these weights (Fig. 1d). In particular, VME at a dose of $100 \mathrm{mg} / \mathrm{kg}$ inhibited the increased weight of all types of adipose tissue. Compared with the HFD group, significant decreases in liver weight were observed in the VME and VMA groups (100 and $200 \mathrm{mg} /$ $\mathrm{kg}$ ) and the OR group (Fig. 1e). VME and VMA (100 mg/ $\mathrm{kg}$ ) slightly reduced spleen and kidney weights, respectively (Fig. 1e). Thus, VME and VMA may decrease body and organ weight without influencing food intake. Neither VME nor VMA induced any adverse effects.

\section{Effects of VME and VMA on serum levels of lipids, tissue function indicators, and adipokines}

Serum triglyceride, free fatty acid, total cholesterol, and LDLcholesterol levels in the HFD group were significantly higher than those in the ND group, but oral administration of VME and VMA decreased these levels (Fig. 2a-b and d-e). Orlistat had similar effects, but total cholesterol and LDL-cholesterol levels did not change in the HCA group. The glucose level in the HFD group was significantly higher than that in the ND group but was decreased by OR, HCA, and VME (100 and $200 \mathrm{mg} / \mathrm{kg}$ ) (Fig. 2c). HDL-cholesterol levels were
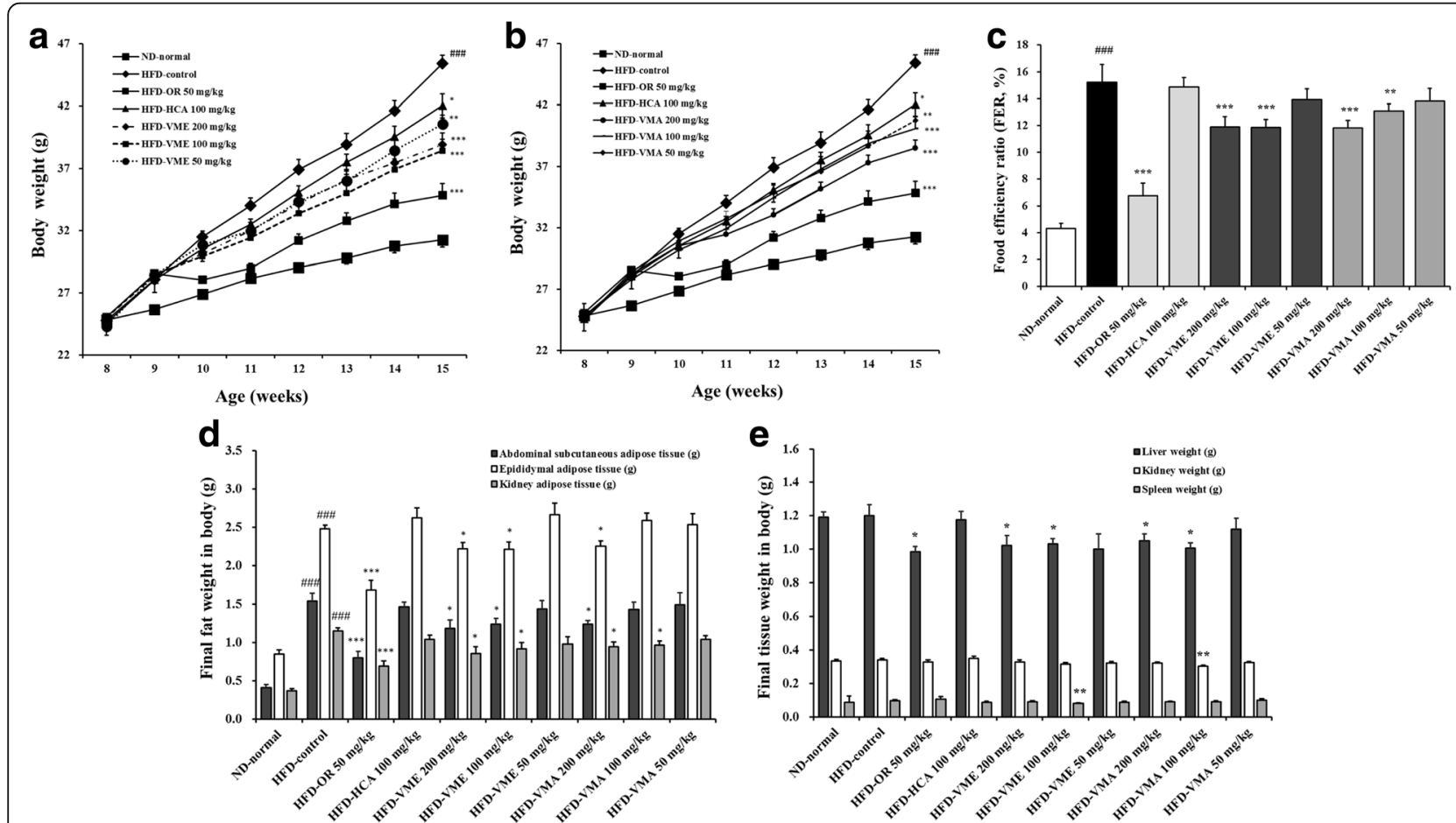

Fig. 1 Effects of VME and VMA on HFD-induced obese mice. a-b Body weight, c FER, d fat weight, and e liver, kidney, and spleen tissue weights. Data are presented as mean \pm SEM $(n=12) ; \# p<0.05$, \#\#p $<0.01$, \#\#\#p $<0.001 \mathrm{vs.} \mathrm{ND-normal;}{ }^{*} p<0.05,{ }^{* *} p<0.01,{ }^{* * *} p<0.001$ vs. HFD-control 

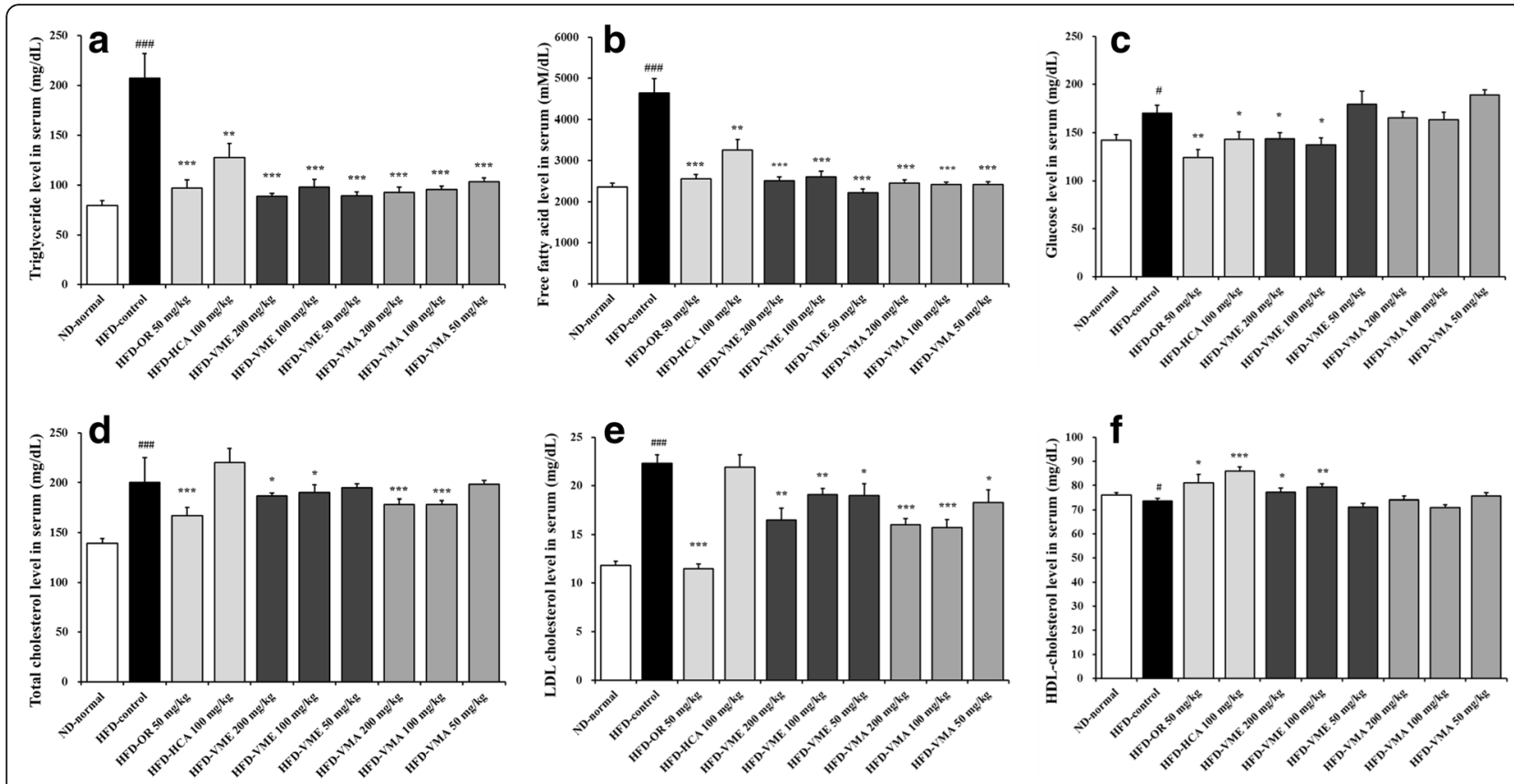

Fig. 2 Effects of VME and VMA on serum lipid levels in HFD-induced obese mice. a Triglyceride, $\mathbf{b}$ free fatty acid, $\mathbf{c}$ glucose, $\mathbf{d}$ total cholesterol, e LDL-cholesterol, and f HDL-cholesterol levels. Data are presented as mean \pm SEM $(n=12)$; \#p $<0.05$, \#\#p $<0.01$, \#\#\#p $<0.001$ vs. ND-normal; ${ }^{*} p<0.05,{ }^{* *} p<0.01,{ }^{* * *} p<0.001$ vs. HFD-control

increased in the HFD-OR, HFD-HCA, HFD-VME $100 \mathrm{mg} /$ $\mathrm{kg}$, and HFD-VME $200 \mathrm{mg} / \mathrm{kg}$ groups (Fig. 2f).

The serum concentrations of creatinine, AST, and ALT were measured as indicators of renal and liver function. Serum creatinine concentrations in the HFD-VME and HFD-VMA groups were significantly decreased relative to the HFD-control group (Fig. 3a). Serum AST levels did not differ among groups. ALT level in the HFDcontrol group was significantly increased, but VME and VMA (200 mg/kg) inhibited the increase in ALT. These results indicate that oral administration of VME or VMA induced no detectable adverse toxic effects in mice.

The mean serum leptin level was significantly higher in the HFD-control group than in the NC-normal group, but leptin levels in VME- and VMA-treated groups were significantly decreased (Fig. 3c). The serum adiponectin level in the HFD group was lower than that in the NC group, but adiponectin level was significantly increased in the VME (50, 100 , and $200 \mathrm{mg} / \mathrm{kg}$ ) and VMA (100 and $200 \mathrm{mg} / \mathrm{kg}$ ) groups as well as the OR and HCA groups (Fig. 3d).

\section{Effects of VME and VMA on adipocyte size}

Histological analysis showed larger adipocyte size in epididymal adipose tissue from the HFD-control group compared with that from the ND-normal group. VME and VMA effectively inhibited the increase in adipocyte size, as did OR and HCA (Fig. 4).
Effects of VME and VMA on mRNA expression levels of lipid metabolism-related genes in epididymal adipose tissue We next analyzed the mRNA levels of genes involved in adipogenesis in adipose tissue after 7 weeks of VME or VMA administration (Fig. 5). mRNA levels of the adipogenic-related transcription factors CCAAT/enhancer binding protein $(\mathrm{CEBP}) \alpha, \mathrm{CEBP} \beta$, and sterol regulatory element-binding protein (SREBP)1c were significantly increased in the HFD group but decreased in the VME and VMA groups compared with those in the ND group (Fig. 5a-c). Thermogenesis-related mitochondrial uncoupling protein (UCP)-2 mRNA expression was significantly decreased in the HFD group and was markedly higher in the VME and VMA groups (Fig. 5d). AMPK $\alpha 1$ and AMPK $\alpha 2$ mRNA levels were significantly increased in the VME and VMA groups (Fig. 5e-f). Moreover, VME and VMA decreased and increased leptin and adiponectin mRNA expression, respectively (Fig. 5g-h).

\section{Effects of VME and VMA on liver histology and AMPK expression}

The effects of VME and VMA on liver morphology and lipid accumulation were determined by $H \& E$ and Oil Red O staining, respectively. The HFD-control group had larger lipid droplets and more excess lipid accumulation than the ND-normal group, but lipid droplet size and lipid accumulation were decreased in VME and VMA groups (Fig. 6). 


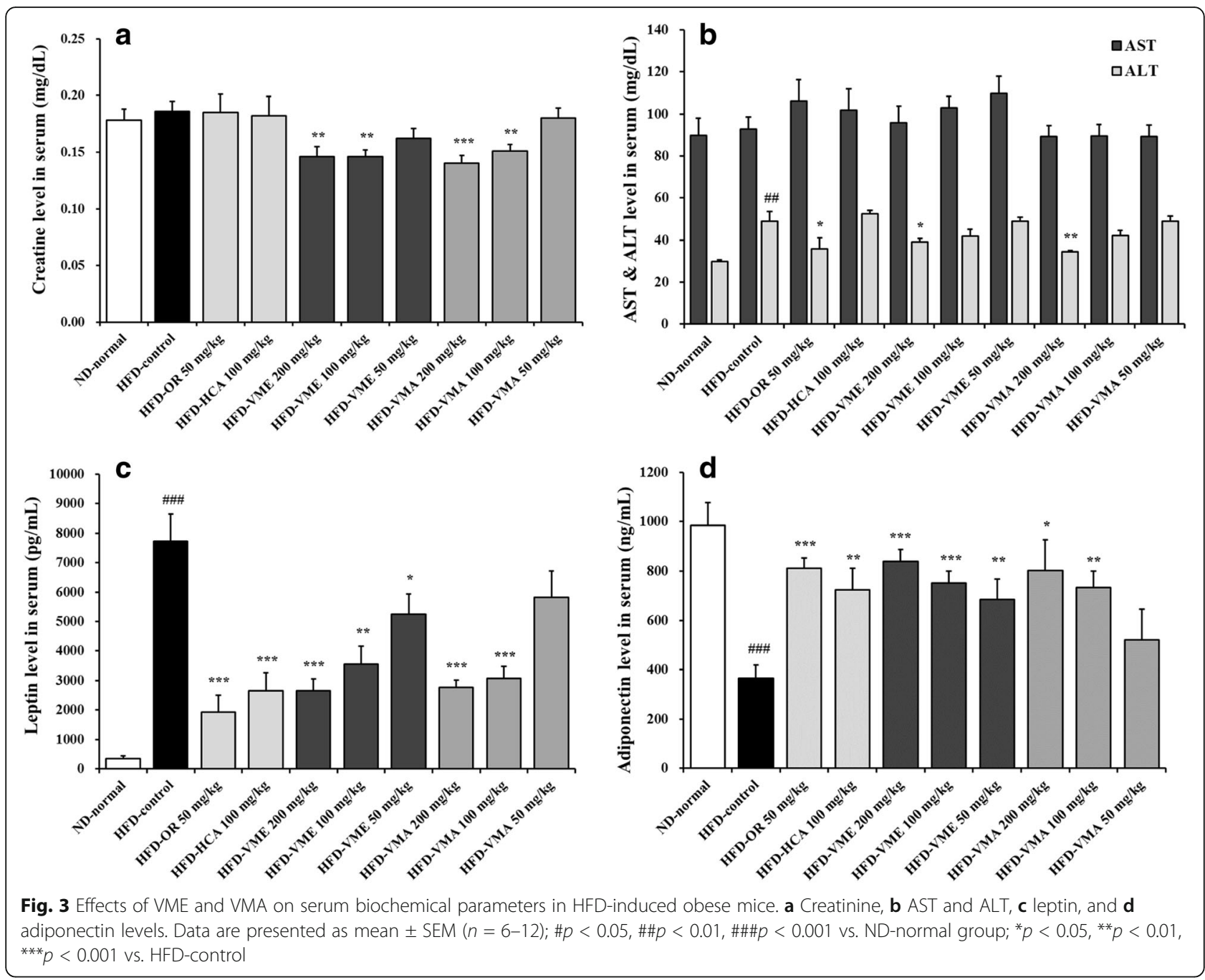

AMPK plays a key role in energy homeostasis and cellular glucose and lipid metabolism [13]. Thus, we investigated whether VME and VMA affect AMPK mRNA expression and activation in the liver. AMPK $\alpha 1$ and AMPK $\alpha 2$ mRNA levels were decreased in the HFD group but were increased in the HFD-VME and HFD-VMA groups (Fig. 7a). VMA only increased the expression of AMPK $\alpha 1$ mRNA. Next, we examined the phosphorylation of AMPK and its downstream target enzyme, ACC (Fig. 7b). The administration of VME and VMA effectively increased the phosphorylation of AMPK and ACC compared with the HFD group, but this effect was stronger for VME.

\section{Chemical composition of VME and VMA}

Quantitative HPLC analysis was performed for standardization of VM extracts. HPLC analysis showed that VME contained $5.66 \pm 0.07 \mathrm{mg} / \mathrm{g}$ esculetin and $1.47 \pm 0.05 \mathrm{mg} / \mathrm{g}$ schaftoside, whereas VMA contained $2.31 \pm 0.03 \mathrm{mg} / \mathrm{g}$ esculetin and $1.26 \pm 0.02 \mathrm{mg} / \mathrm{g}$ schaftoside (Fig. 7c).

\section{Acute toxicity test}

An acute toxicity test revealed that oral administration of a single $5000 \mathrm{mg} / \mathrm{kg}$ dose of VME or VMA induced no signs of toxicity, body weight change, or mortality in rats during a 14-day observation period.

\section{Discussion}

We investigated the anti-obesity and lipid-lowering effects of two $V$. mandshurica extracts in HFD-induced obese mice. After 7 weeks, VME and VMA decreased body weight gain, FER, fat and liver masses, serum lipid levels, and adipocyte size relative to HFD mice. The expression of lipid metabolism-related genes and AMPK, an important energy regulator, were significantly altered in VME- and VMAtreated HFD mice. By contrast, HCA, a positive control compound extracted from Garcinia cambogia fruit, significantly decreased body weight and serum triglyceride but did not dramatically affect the food efficiency ratio, fat mass, or serum total cholesterol and LDL-cholesterol levels. These 


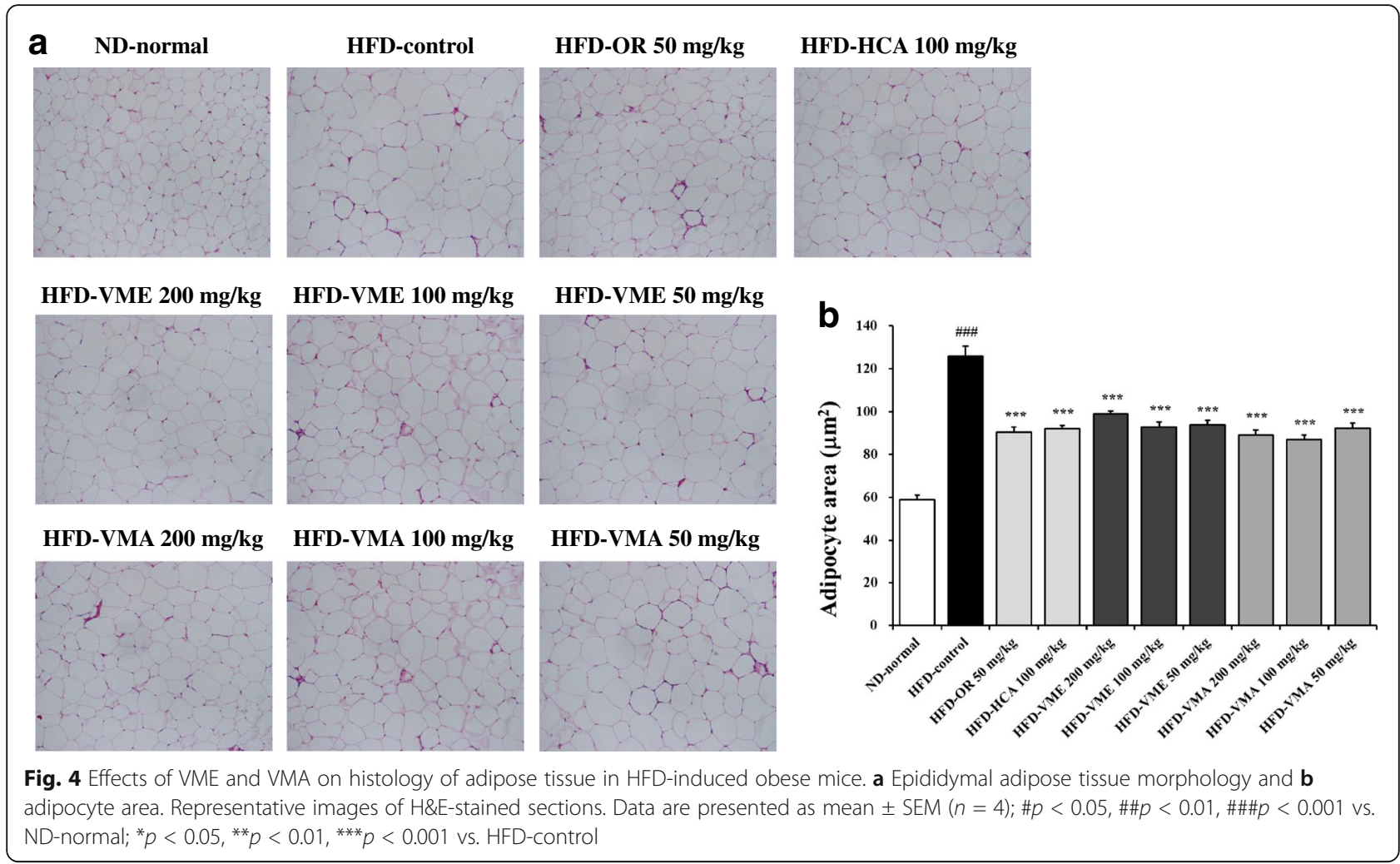

results suggest that both VM extracts have potent antiobesity effects.

To elucidate the mechanisms by which VME and VMA exert anti-obesity effects, we investigated lipid metabolism and AMPK signaling in the liver and adipose tissue. Activation of AMPK in both types of tissue plays a major role in regulating glucose and lipid metabolism via the stimulation of fatty acid oxidation and inhibition of lipogenesis and glucose production $[14,15]$. Given the role of AMPK signaling pathway-related proteins in glucose and lipid metabolism, it is important to identify and analyze their mRNA and protein expression levels in adipose tissue and the liver. Thus, we

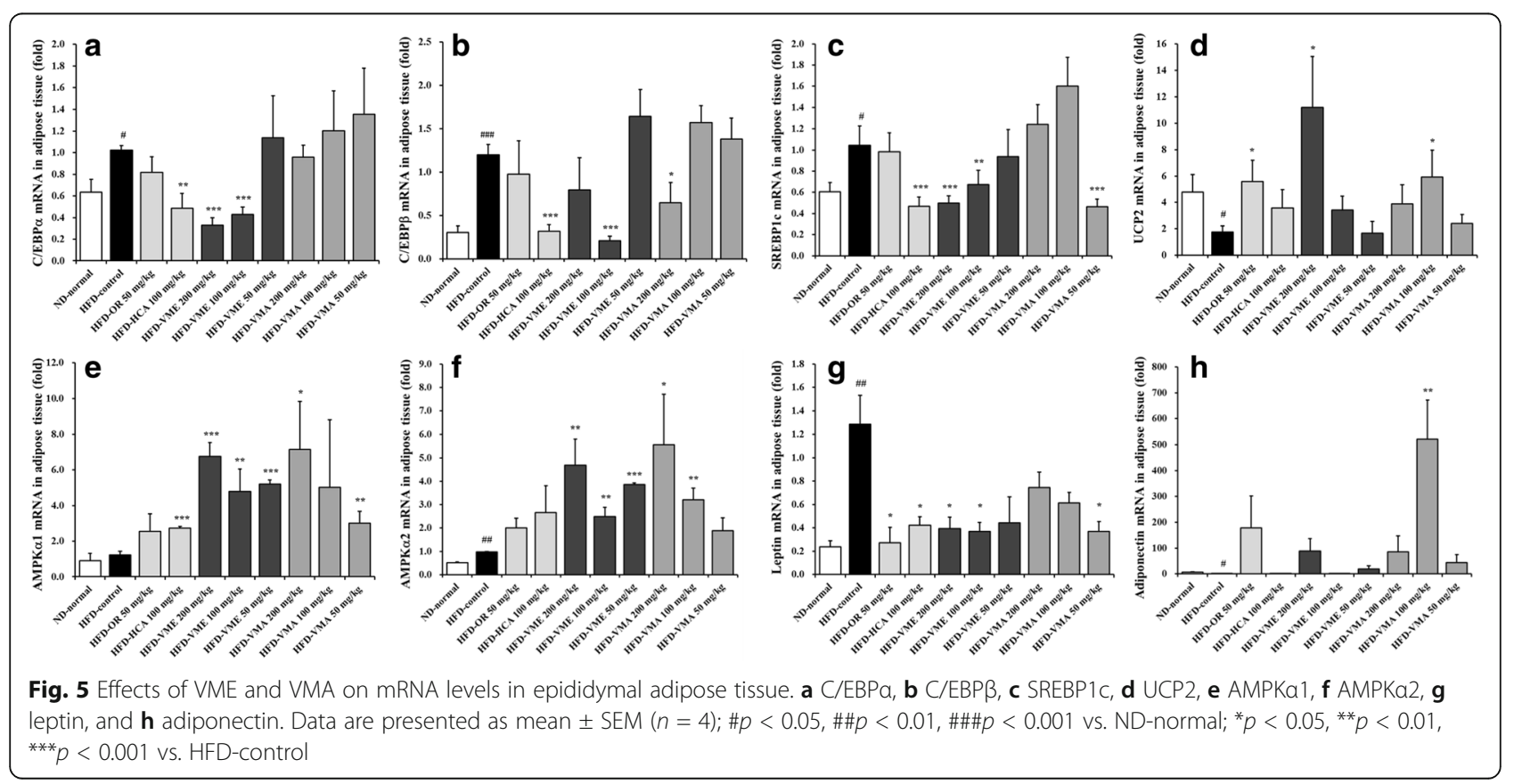




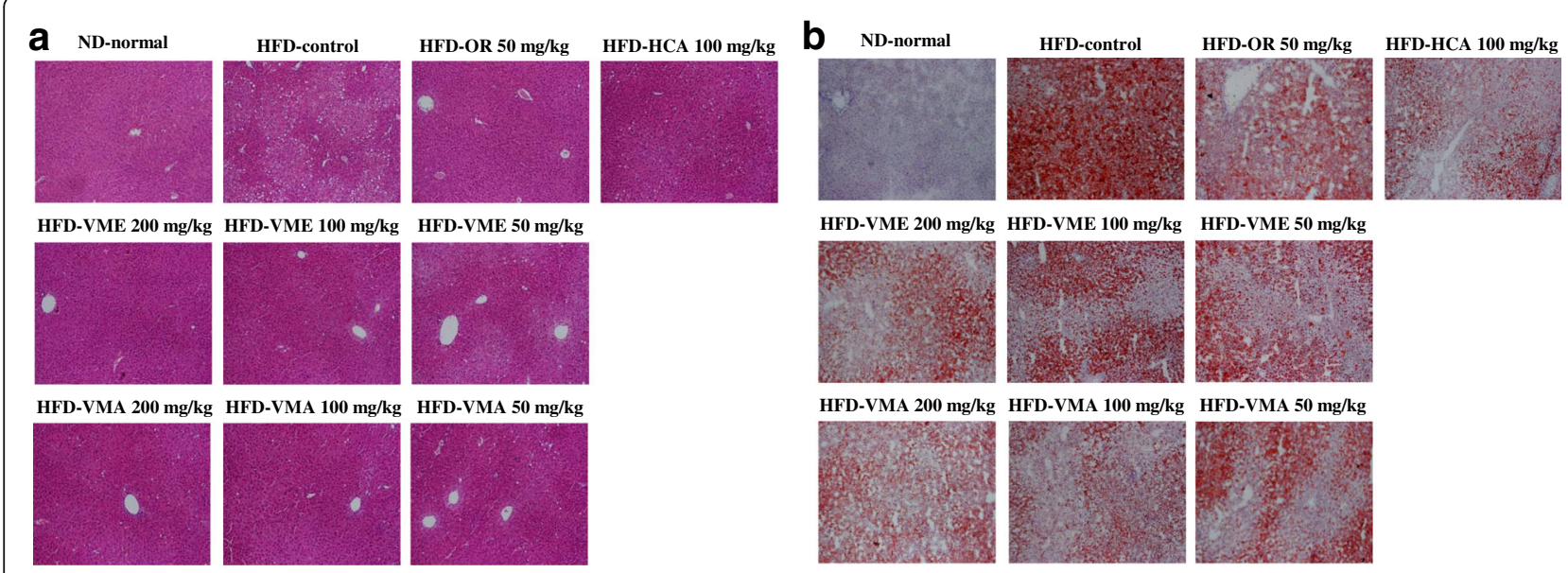

Fig. 6 Effects of VME and VMA on liver morphology in HFD-induced obese mice. Tissue sections stained with a H\&E and b Oil Red O

investigated whether VME and VMA affect mRNA expression and activation of AMPK and AMPK signaling pathway-related-proteins in these tissues. Gene expression analyses showed that VME and VMA decreased the mRNA levels of lipogenic genes such as $\mathrm{C} / \mathrm{EBP} \alpha, \mathrm{C} / \mathrm{EBP} \beta$, SREBP1c, and leptin in the epididymal adipose tissue of HFD-induced obese mice. VME and VMA also increased mRNA levels of the thermogenesis-related protein UCP2 [16] along with AMPK $\alpha 1$ and AMPK $\alpha 2$ in adipose tissue. In addition, VME and VMA markedly increased adiponectin serum levels and mRNA expression in adipose tissue. The effects of fat cell-derived adiponectin on insulinsensitizing and fatty-acid-oxidizing actions is dependent on AMPK activation (i.e., phosphorylation) in the adipose tissue and liver $[17,18]$. We previously reported that VME induces AMPK activation and inactivation of ACC, a downstream target of AMPK, in adipose tissue [11]. In the present study, we demonstrated that mRNA and phosphorylation of AMPK $\alpha$ decreased in the liver of obese mice, suggesting that alterations in AMPK $\alpha$ expression

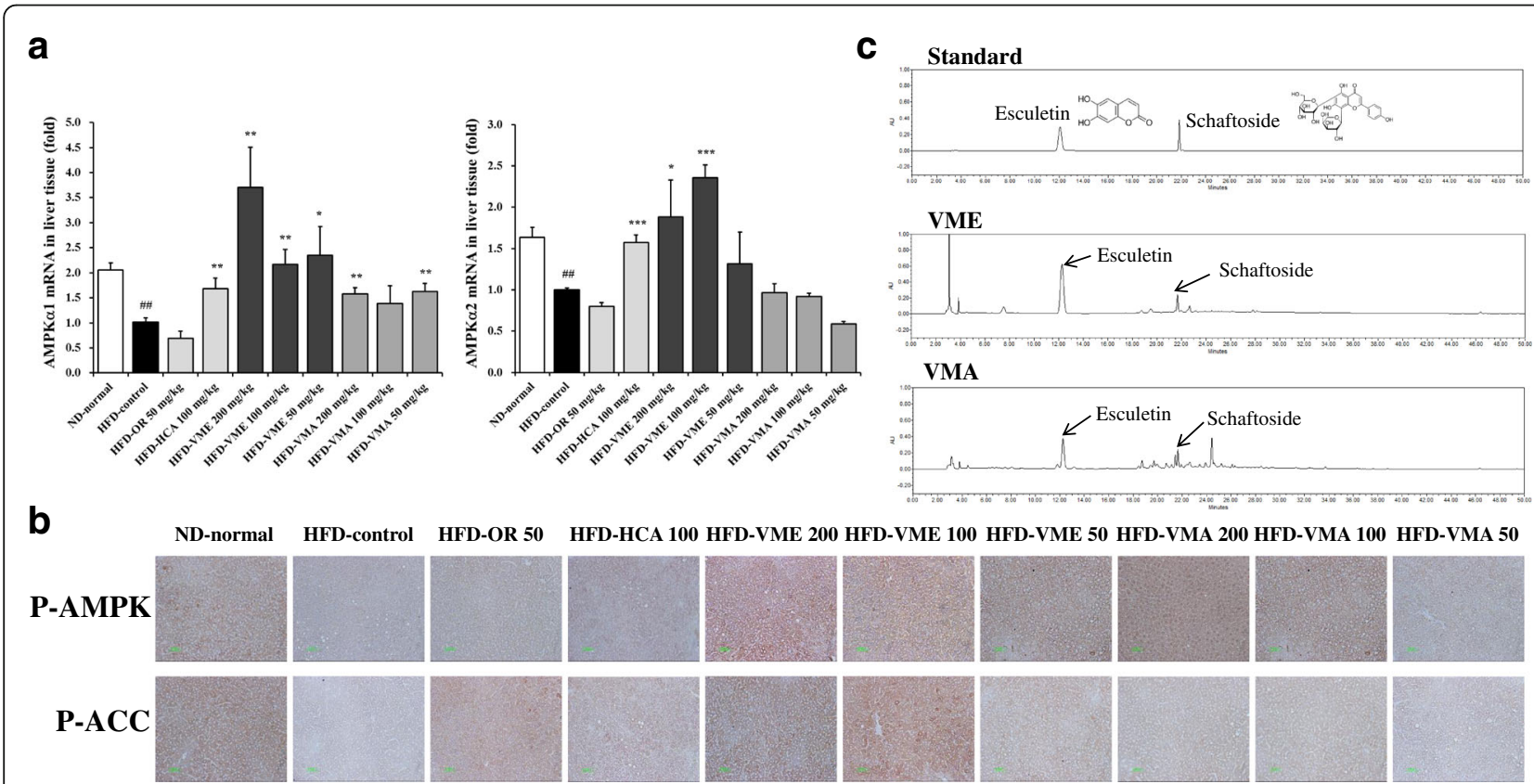

Fig. 7 Effects of VME and VMA on hepatic AMPK expression and HPLC chromatogram. a AMPKa1 and AMPKa2 mRNA expression and $\mathbf{b}$ AMPK and ACC phosphorylation. c HPLC-PDA chromatograms of two standards mixture, VME, and VMA at $330 \mathrm{~nm}$. Esculetin and schaftoside appeared at retention times of approximately 12.3 and $21.7 \mathrm{~min}$, respectively. Data are presented as mean \pm SEM $(n=4) ; \# p<0.05, \# \# p<0.01$, $\# \#$ \#\# 0.001 vs. ND-normal; ${ }^{*} p<0.05,{ }^{* *} p<0.01,{ }^{* * *} p<0.001$ vs. HFD-control 
contribute to the pathogenesis of lipid accumulation in the liver of obese mice. However, VME and VMA stimulated AMPK expression and activation and inhibited ACC activation in the liver, suggesting that VME and VMA improve abnormal lipid metabolism by suppressing lipogenesis and promoting fatty acid oxidation via up-regulation of AMPK.

HPLC analysis revealed that both VME and VMA contain esculetin and schaftoside. Esculetin reportedly inhibits adipogenesis in 3 T3-L1 adipocytes [11, 19]. Esculetin at a concentration of $10 \mu \mathrm{g} / \mathrm{mL}$ inhibits adipocyte differentiation to $31 \%$ of fully differentiated cells, whereas VME at the same concentration has no significant effect [11]. Oral administration of esculetin $(30 \mathrm{mg} / \mathrm{kg}$ ) to HFD-induced obese mice decreases body weight and reduces serum levels of total triglyceride, total cholesterol, and glucose [20]. The free hydroxyl groups in the chemical structures of these coumarin compounds are favorable for anti-adipogenesis activity and lipolysis [20]. Recently, the c-glycosylflavone compound schaftoside was reported to exhibit pancreatic lipase inhibitory activity [21]. We found that the amount of esculetin in VME was 2.14-fold greater than that in VMA, which might be one reason for the greater suppressive effect of VME on fat accumulation in adipose tissue. These results suggest that esculetin and schaftoside are partly responsible for the anti-obesity effects of VM extracts. However, we did not determine whether the effects of VMA and VME are dependent on these two compounds because we administered a complex mixture to the mice. Previous phytochemical studies show that Herba Violae mainly contains several flavonoids, coumarins, and organic acids [22]. Thus, further studies are needed to determine the antiobesity effects of particular components through the phytochemical analysis of bioactive compounds in VM extracts.

Oral administration of a single $5000 \mathrm{mg} / \mathrm{kg}$ dose of VME or VMA caused no signs of toxicity or mortality in ten rats. Thus, the $\mathrm{LD}_{50}$ values of VME and VMA are likely higher. Compounds with an $\mathrm{LD}_{50}$ over $2000 \mathrm{mg} /$ $\mathrm{kg}$ are considered relatively safe according to the Globally Harmonized System of Classification and Labelling of Chemicals [23] and acute toxicity guidelines of the Organization for Economic Cooperation and Development [24]. Hence, these results suggest that both VM extracts are reasonably safe for traditional medical use.

\section{Conclusions}

Oral VME and VMA reduced body weight gain, fat mass, and serum lipid concentrations in HFD-induced obese mice. A single $5000 \mathrm{mg} / \mathrm{kg}$ dose of these extracts appeared to have no adverse effects in rats. Overall, our findings suggest that VME and VMA exert anti-obesity effects in HFD-induced obese mice by activating AMPK and suppressing lipid metabolism in adipose tissue and the liver. Therefore, VME and VMA should be further investigated as anti-obesity and anti-hyperlipidemia agents.

\section{Abbreviations}

ACC: acetyl-coA carboxylase; ALT: alanine aminotransferase; AMPK: adenosine monophosphate-activated protein kinase; AST: aspartate aminotransferase; C/ EBP: CCAAT/enhancer binding protein; GAPDH: glyceraldehyde-3-phosphate dehydrogenase; HCA: hydrocitric acid; HDL: high-density lipoprotein; HFD: high-fat diet; LD: lethal dose; LDL: low-density lipoprotein; ND: normal diet; OR: orlistat; SREBP1c: sterol regulatory element-binding protein1c; UCP: uncoupling protein; VMA: Viola manshurica aqueous extract; VME: Viola mandshurica ethanolic extract

\section{Acknowledgments}

Not applicable.

\section{Funding}

This study was supported by project (G15110) "Development of natural functional food for weight loss" from the INNOPOLIS foundation of Korea and project (K14223) "Technical commercialization of anti-obesity material" from the Korea Institute of Oriental Medicine of Korea. The funders had no role in the design of the study; the collection, analysis, or interpretation of the data; or the writing of the manuscript.

\section{Availability of data and materials}

All data generated or analyzed during this study are included in the published article.

\section{Authors' contributions}

YYS and HYK participated in the design of the study. YYS carried out the experiments, analyzed the data, and wrote the manuscript. DSK carried out the HPLC analysis. SHK carried out the animal studies. All authors read and approved the final manuscript.

\section{Competing interests}

The authors declare that they have no competing interests.

\section{Consent for publication}

Not applicable.

\section{Ethical approval}

All animal studies were approved by the Committee on Animal Care of the Daejeon University (Permit No. DJUARB2014-042).

\section{Publisher's Note}

Springer Nature remains neutral with regard to jurisdictional claims in published maps and institutional affiliations.

\section{Author details}

${ }^{1}$ Mibyeong Research Center, Korea Institute of Oriental Medicine, 1672 Yuseong-daero, Yuseong-gu, Daejeon 305-811, Republic of Korea. ${ }^{2}$ KM Convergence Research Division, Korea Institute of Oriental Medicine, Daejeon 305-811, Republic of Korea. ${ }^{3}$ Institute of Traditional Medicine and Bioscience, Daejeon University, Daejeon 300-716, Republic of Korea.

Received: 20 February 2017 Accepted: 26 May 2017

Published online: 06 June 2017

\section{References}

1. Wu T, Qi X, Liu Y, Guo J, Zhu R, Chen W, et al. Dietary supplementation with purified mulberry (Morus australis Poir) anthocyanins suppresses body weight gain in high-fat diet fed C57BL/6 mice. Food Chem. 2013;141:482-7.

2. Lee YS, Cha BY, Saito K, Choi SS, Wang XX, Choi BK, et al. Effects of a Citrus depressa Hayata (shiikuwavsa) extract on obesity in high-fat diet-induced obese mice. Phytomedicine. 2011;18:648-54.

3. Kakkar AK, Dahiya N. Drug treatment of obesity: current status and future prospects. Eur J Intern med. 2015;26:89-94.

4. Balaji M, Ganjayi MS, Hanuma Kumar GE, Parim BN, Mopuri R, Dasari S. A review on possible therapeutic targets to contain obesity: the role of phytochemicals. Obes res Clin Pract. 2016;10:363-80.

5. Pucci A, Finer N. New medications for treatment of obesity: metabolic and cardiovascular effects. Can J Cardiol. 2015;31:142-52.

6. Sethi A. A review on "Garcinia cambogia - a weight controlling agent". Int J Pharm res dev. 2011;3:13-24. 
7. Fassina P, Scherer Adami F, Terezinha Zani V, Kasper Machado IC, Garavaglia J, Quevedo Grave MT, et al. Morelo dal Bosco S. The effect of Garcinia cambogia as coaduvant in the weight loss process. Nutr Hosp. 2015;32:2400-8.

8. Jeon GI, Yoon MY, Park HR, Lee SC, Park E. Neuroprotective activity of Viola mandshurica extracts on hydrogen peroxide-induced DNA damage and cell death in PC12 cells. Ann N York Acad Sc. 2009;1171:576-82.

9. Lee BW, Kim DH. Inhibitory effect of Violae herba extract on inflammatory cytokine production by IL-1 $\beta$ and TNF-a in cultured human synovial cells. Kor J Herbology. 2003;18:89-96.

10. Lee MY, Yuk JE, Kwon OK, Kim HS, Oh SR, Lee HK, et al. Anti-inflammatory and anti-asthmatic effects of Viola mandshurica W. Becker (VM) ethanolic (EtOH) extract on airway inflammation in a mouse model of allergic asthma. J Ethnopharmacol. 2010;127:159-64.

11. Sung YY, Kim DS, Kim HK. Viola mandshurica ethanolic extract prevents high-fat-diet-induced obesity in mice by activating AMP-activated protein kinase. Environ Toxicol Pharmacol. 2014;38:41-50.

12. Choi $\mathrm{H}$, Eo H, Park K, Jin M, Park EJ, Kim SH, et al. A water-soluble extract from Cucurbita moschata shows anti-obesity effects by controlling lipid metabolism in a high fat diet-induced obesity mouse model. Biochem Biophys res Commun. 2007;359:419-25.

13. Towler MC, Hardie DG. AMP-activated protein kinase in metabolic control and insulin signaling. Circ res. 2007;100:328-41.

14. Kim SJ, Jung JY, Kim HW, Park T. Anti-obesity effects of Juniperus chinensis extract are associated with increased AMP-activated protein kinase expression and phosphorylation in the visceral adipose tissue of rats. Biol Pharm Bull. 2008:31:1415-21.

15. Viollet B, Foretz M, Guigas B, Horman S, Dentin R, Bertrand L, et al. Activation of AMP-activated protein kinase in the liver: a new strategy for the management of metabolic hepatic disorders. J Physiol. 2006;574:41-53.

16. Dulloo AG, Seydoux J, Jacquet J. Adaptive thermogenesis and uncoupling proteins: a reappraisal of their roles in fat metabolism and energy balance. Physiol Behav. 2004;83:587-602.

17. Yamauchi T, Kamon J, Minokoshi Y, Ito Y, Waki H, Uchida S, et al. Adiponectin stimulates glucose utilization and fatty-acid oxidation by activating AMP-activated protein kinase. Nat med. 2002;8:1288-95.

18. Wu X, Motoshima H, Mahadev K, Stalker TJ, Scalia R, Goldstein BJ. Involvement of AMP-activated protein kinase in glucose uptake stimulated by the globular domain of adiponectin in primary rat adipocytes. Diabetes. 2013;52:1355-63.

19. Yang JY, Della-Fera MA, Hartzell DL, Nelson-Dooley C, Hausman DB, Baile CA. Esculetin induces apoptosis and inhibits adipogenesis in 3T3-L1 cells. Obesity (Silver Spring). 2006;14:1691-9.

20. Karmase A, Birari R, Bhutani KK. Evalution of anti-obesity effect of Aegle marmelos leaves. Phytomedicine. 2013;20:805-12.

21. Tao Y1, Cai H, Li W, Cai B. Ultrafiltration coupled with high-performance liquid chromatography and quadrupole-time-of-flight mass spectrometry for screening lipase binders from different extracts of Dendrobium officinale. Anal Bioanal Chem. 2015:407:6081-93.

22. Hong JL, Zhou HY, Zhu J, Li L, Shu P, Qin XY, et al. Comparative analysis of major constituents in Viola yedoensis Makino and different species from the genus Viola by high-performance liquid chromatography with chemometrics methods. J med Plants res. 2011;5:5230-9.

23. United Nations. Globally Harmonized System of Classification and Labelling of Chemicals (GHS). 4rd ed. New York and Geneva:United Nations; 2011. p. 109-110

24. Organization for Economic Cooperation and Development (OECD). OECD guideline for testing of chemicals. No. 423. Acute oral toxicity-acute classic method. Paris: OECD; 2001.

\section{Submit your next manuscript to BioMed Central and we will help you at every step:}

- We accept pre-submission inquiries

- Our selector tool helps you to find the most relevant journal

- We provide round the clock customer support

- Convenient online submission

- Thorough peer review

- Inclusion in PubMed and all major indexing services

- Maximum visibility for your research

Submit your manuscript at www.biomedcentral.com/submit
Biomed Central 